University of Wollongong

Research Online

Faculty of Engineering and Information

Faculty of Engineering and Information

Sciences - Papers: Part A

Sciences

$1-1-2015$

Enhanced frequency response strategy for PMSG based wind energy conversion system using ultracapacitor in remote area power supply systems

Yingjie Tan

University of Wollongong, yt816@uowmail.edu.au

Kashem M. Muttaqi

University of Wollongong, kashem@uow.edu.au

Follow this and additional works at: https://ro.uow.edu.au/eispapers

Part of the Engineering Commons, and the Science and Technology Studies Commons

Research Online is the open access institutional repository for the University of Wollongong. For further information contact the UOW Library: research-pubs@uow.edu.au 


\title{
Enhanced frequency response strategy for PMSG based wind energy conversion system using ultracapacitor in remote area power supply systems
}

\author{
Abstract \\ The high penetration level of wind energy, and non-responsive nature of power electronic interfaced wind \\ energy conversion system (WECS) during frequency variations may create significant stress on \\ conventional generators in a wind-diesel hybrid remote area power supply (RAPS) system. Hence, it is a \\ necessity for WECS to provide frequency support. However, conventional frequency control strategies \\ being used for WECS may impose a severe stress to wind turbines. In this paper, an enhanced frequency \\ response strategy is proposed for the permanent magnet synchronous generator (PMSG) based WECS to \\ regulate RAPS system frequency jointly with its integrated ultracapacitors. The proposed frequency \\ response strategy utilizes the droop control and virtual inertial techniques while suboptimal power point \\ tracking (SOPPT) is implemented in WECS. It can effectively regulate RAPS system frequency while \\ alleviating high rate of change of power (ROCOP) and thus torque stress on both the conventional \\ generators and wind turbines under frequency disturbances.
}

\section{Keywords}

wind, pmsg, system, ultracapacitor, remote, area, power, supply, strategy, systems, response, frequency, conversion, enhanced, energy

\section{Disciplines \\ Engineering | Science and Technology Studies}

\section{Publication Details}

Y. Tan \& K. M. Muttaqi, "Enhanced frequency response strategy for PMSG based wind energy conversion system using ultracapacitor in remote area power supply systems," in ndustry Applications Society Annual Meeting, 2015 IEEE, 2015, pp. 1-8. 


\section{Enhanced Frequency Response Strategy for PMSG based Wind Energy Conversion System using Ultracapacitor in Remote Area Power Supply Systems}

\author{
Yingjie Tan \\ Graduate Student Member, IEEE \\ School of Electrical, Computer and \\ Telecommunications Engineering \\ University of Wollongong \\ New South Wales 2500, Australia \\ yt816@uowmail.edu.au
}

\author{
Kashem M. Muttaqi \\ Senior Member, IEEE \\ School of Electrical, Computer and \\ Telecommunications Engineering \\ University of Wollongong \\ New South Wales 2500, Australia \\ kashem@uow.edu.au
}

\begin{abstract}
The high penetration level of wind energy, and non-responsive nature of power electronic interfaced wind energy conversion system (WECS) during frequency variations may create significant stress on conventional generators in a wind-diesel hybrid remote area power supply (RAPS) system. Hence, it is a necessity for WECS to provide frequency support. However, conventional frequency control strategies being used for WECS may impose a severe stress to wind turbines. In this paper, an enhanced frequency response strategy is proposed for the permanent magnet synchronous generators (PMSG) based WECS to regulate RAPS system frequency jointly with its integrated ultracapacitors. The proposed frequency response strategy utilizes the droop control and virtual inertial techniques while suboptimal power point tracking (SOPPT) is implemented in WECS. It can effectively regulate RAPS system frequency while alleviating high rate of change of power (ROCOP) and thus stress on both the conventional generators and wind turbines under frequency disturbances.
\end{abstract}

Keywords - frequency response, permanent magnet synchronous generator, remote area power supply system, ultracapacitor, wind generation.

\section{INTRODUCTION}

Remote area power supply (RAPS) system operates in a similar way as an islanded 'Microgrid', and supplies power to the 'isolated' (e.g. offshore) communities where utility grid is not accessible [1]. Due to the growing interest in renewable power, the penetration of renewable energy resources in the RAPS system can be at a significant level, which challenges the management of the RAPS system. For example, due to the isolation between renewable generators and the grid through power electronic interfaces, the reduction in system inertia burdens the existing synchronous generator like diesel generator to handle the frequent frequency fluctuations and may lead to system frequency instability. Consequently, there is an urgent need for renewable generators such as wind energy conversion system (WECS) to participate in frequency regulation in combination with synchronous generators.

Doubly fed induction generator (DFIG) based WECS has been widely investigated on its frequency support in power systems [2-6]. However, since the partial scale power electronic converters of the DFIGs are normally designed to be rated at $20 \%-30 \%$ of the full rating of the generator, the turbine rotor speed can only be operated between 0.67 p.u.-1.33p.u. [6] and the design constrains, such as the maximum power output, limit the frequency response capability of the DFIGs. In particular, when rotor speed control is applied to 'deload' [7] the WECS and reserve part of the wind power, rotor speed increases above or decreases below the rotor speed at the maximum power point (MPP) and requires a wider speed range. Permanent magnetic synchronous generator (PMSG) based WECS also apply power electronic converters to couple with the grid, which enables the PMSGs to operate in variable speed mode and maximize their energy extraction from the wind. Unlike DFIGs with stator connected to the grid directly, PMSGs are totally decoupled from the system frequency by the back-to-back converter scheme and present no natural frequency response whereas DFIGs actually show some inertia response under frequency event [8]. Furthermore, the full scale power converter design enables the PMSGs to operate in wider speed range [9], and benefits the frequency response. Therefore, it is worthwhile to further explore the frequency response capability of PMSG base WECS.

Frequency response capability of PMSG based WECS is studied in [10], and a control scheme with virtual inertia and droop control is implemented to extract the kinetic energy. It is found that the frequency control performance can be comparable with conventional synchronous generators, but special attention should be paid for ending the frequency support from PMSGs to prevent the reduction in PMSG power output after the frequency event. In [11], PMSG exports constant power when available wind power exceeds a particular percentage of the rated power and hence energy reserve is constituted. With the power reserve, the PMSG shifts the power output with droop control when imbalance between generation and load demand occurs. However, considering the randomness of the wind speed and the resulting unreliable energy reserve, the participation of PMSGs in load sharing with droop control may cause stability problems. Authors in [12] propose a general control scheme for variable speed WECS (i.e. DFIG based WECS and PMSG based WECS).

In the aforementioned research work, there exists a common limitation that the mechanical stress on the drivetrain of the WECS is not considered. Due to the fast 
response speed of the power electronics, the PMSG based WECS handles frequency support and can be significantly burdened although the torque stress on conventional generators is relieved. The frequent abrupt torque variation on the drivetrain may increase operation and maintenance (O\&M) cost of the mechanical components, particularly when gear presents in the system. In order to address this problem, a limit on the rate of change power (ROCOP) is set for the variable speed WECS to reduce mechanical stresses on the drive train as suggested in [13]. However, the ROCOP limits inevitably compromise the frequency response of the generator.

Ultracapacitor (UC) is featured with low energy density, high power density, and fast charge/discharge rates [14], which labels UC as an ideal storage for providing short term frequency response. In [15], UC is integrated into the DFIGs based WECS to smooth the wind power fluctuations and enhance the low voltage ride through capability. A combination of battery and UC is used for power management in a DFIG based WECS in [16], for which a fuzzy logic controller is developed and applied to improve the energy management. UC has also been utilized in PMSG based WECS. In [17], a probabilistic method is proposed to determine the capacities of the battery energy storage system and UC to limit the wind power fluctuation within a certain value. A similar study is carried out in [18], but zinc bromide flow battery and lithium-ion capacitors are used as hybrid storage system to constrain the wind power output ramp rates. However, all these research works do not explore the effect of UC on the transient performance of the wind energy conversion system. The implementation of UC in frequency response has not been investigated neither.

Additionally, another limitation in the aforementioned research work is that two full controlled converters are used for the back-to-back AC/DC/AC converter scheme (i.e. rectifier and inverter) in the PMSG based WECS. The converter scheme with diode rectifier, boost converter, and inverter is not studied for the application in frequency regulation. This paper utilizes UC in the PMSG based WECS to provide short term frequency response. It enables to relieve the mechanical stress on both the conventional generator and wind turbine generators while providing frequency support. Also, the PMSG in the target RAPS system is interfaced to the grid through an AC/DC/AC converter scheme consisting of a diode rectifier, a boost converter, and an inverter. Furthermore, by reserving a part of wind power in the PMSG based WECS, the reserved energy can be extracted to charge the UC and enhance the frequency response supplied by UC.

The remainder of the paper is organized as follows. Section II introduces the architecture of the RAPS system considered and modelling of main system components. Section III discusses the power reserving approach for WECS. In Section IV, a comparative analysis is carried out to discuss frequency response control strategies for the PMSG based WECS. Also, in this section, a primary frequency controller based on UC is proposed. Section V presents the results and discussions. Conclusions are drawn in Section VI.

\section{RAPS SYSTEM MODELLING}

\section{A. RAPS system architecture}

A RAPS system which consists of a diesel generator and two PMSG based WECS is used as a test system (see Fig. 1) to validate the applicability of the proposed control strategies. Such kind of test system has been widely used in literature to test the frequency response controllers [5, $19,20]$. On the one hand, frequency variations are more frequent and higher (as high as $1 \mathrm{~Hz}$ ) in such isolated system of small generating capacity. On the other hand, instead of having an infinite bus to generate a frequency event passively, the frequency dynamics can be easily observed and the contribution of the controller to the frequency regulation can be easily determined with such a moderately sized RAPS system. The $11 \mathrm{kV}$ network parameters marked on the diagram in Fig. 1 are obtained from [21].

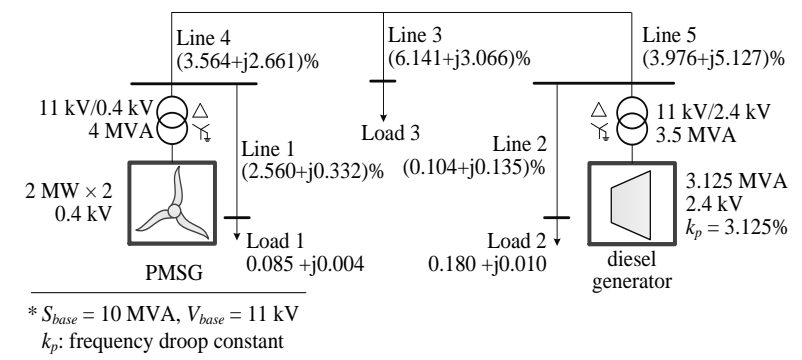

Fig. 1 RAPS system architecture.

\section{B. Diesel generator}

The diesel generator is used to improve the reliability of the RAPS system and regulate system voltage within the stipulated limits (e.g. $1 \pm 5 \%$ p.u.) while fulfilling the reactive power requirement of the RAPS system. Moreover, the diesel generator is operated with droop control to support system frequency. Generally, droop settings for generators in power systems are in the range of $3 \%-6 \%$ [6]. In this RAPS model, the droop coefficient for the diesel generator is set at $3.125 \%$ (i.e. $2 \mathrm{MW} / \mathrm{Hz}$ ). The dynamic models and parameters for the diesel engine governor, synchronous machine and its exciter are obtained from [22].

\section{PMSG based WECS}

A detailed model for the PMSG based WECS is used in this paper as shown in Fig. 2. The machine side converter (MSC) of the back-to-back converter scheme is an uncontrolled diode bridge to rectify the three phase voltage produced by PMSG. The output DC voltage is converted to the DC-link rated voltage with the boost converter. The grid side converter (GSC) consisting of a full controlled bridge inverts the DC voltage and couples to the grid through filter. The inverter is controlled in the grid voltage oriented reference frame with d-axis a aligned with grid voltage. The d-axis component and q-axis component of the current can control the active power and reactive power respectively. Since diesel generator meets all the reactive 
power demand in this study, the PMSG based WECS is operated at the unity power factor. The pitch angle control of PMSG based WECS is activated when the power output exceeds the maximum limit. The UC is utilized for frequency response and it is mounted on the DC-link through a bidirectional DC/DC converter. The disadvantage of this configuration is that no additional inverter is required to connect UC to the grid. The equivalent circuit of the UC is presented as a series connection of resistor and capacitor [17].

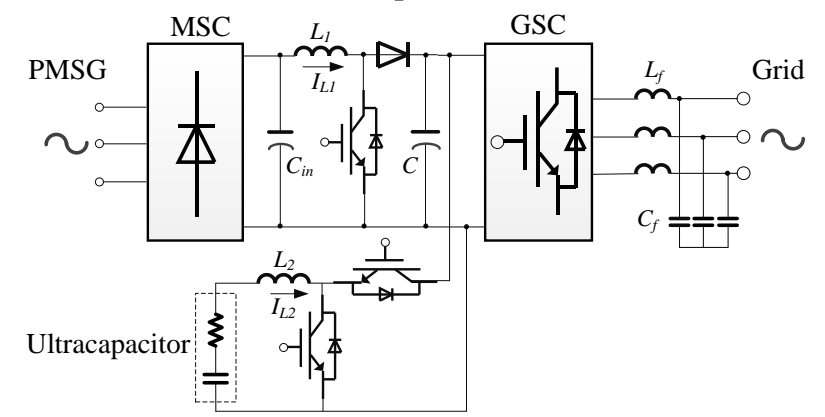

Fig. 2 PMSG based wind turbine generator configuration.

\section{Suboptimal POWER POINT TRACKING STRATEGY}

For renewable power generators to participate in frequency regulation, the frequency response cannot be sustained indefinitely if only kinetic energy serves the frequency response. Therefore, generators must maintain energy reserve to provide long term frequency response. Hence, instead of operating at maximum power point tracking (MPPT) strategy, renewable power generators should be deliberately operated below their MPP. In the published literature, this strategy is commonly referred as 'de-loaded' control [6] or suboptimal power point tracking (SOPPT) control [23].

In regard to the WECS, mechanical power output of a wind turbine can be determined by Eqn. (1) [17].

$$
\begin{gathered}
P=1 / 2 \rho \pi R^{2} v^{3} C_{p}(\lambda, \beta) . \\
\lambda=\frac{\omega_{r} R}{v} .
\end{gathered}
$$

where $\rho$ is the air density usually taken as $1.225 \mathrm{~kg} / \mathrm{m}^{3}, R$ is rotor radius, $v$ is the wind speed at the hub height, $\omega_{r}$ is the rotor speed, and $C_{p}(\lambda, \beta)$ is the power efficiency of the wind turbine, which is a function of tip-speed-ratio $\lambda$ (as given by (2)) and pitch angle $\beta$. Wind turbines are usually operated at their MPPT to maximize their power production by controlling $\lambda$ and $\beta$ at their optimal value. The solid red line in Fig. 3 indicates the typical MPPT curve for tracking the maximum wind power. When SOPPT control is active, wind power reserve $P_{\text {res }}$ can be determined by

$$
P_{r e s}=1 / 2 \rho \pi R^{2} v^{3}\left[C_{p}\left(\lambda_{1}, \beta_{1}\right)-C_{p}\left(\lambda_{2}, \beta_{2}\right)\right] .
$$

where, $C_{p}\left(\lambda_{1}, \beta_{1}\right)$ and $C_{p}\left(\lambda_{2}, \beta_{2}\right)$ are the wind turbine power efficiency under typical MPPT control and SOPPT control respectively. Delta control approach [12] is used to reserve a constant power of 0.01 p.u. on the base of rated power of the wind turbine in this paper. As it can be seen from Fig. 3, the SOPPT curve with 0.01 p.u. power reserve can be on either side of the typical MPPT curve. The right side SOPPT curve, as indicated by green dash-dot line in Fig. 3, is chosen in this paper. The reason is that kinetic energy is released to enhance frequency response when wind generator is providing frequency support by lowering its rotor speed and increasing the power output. The right side SOPPT curve is represented by Eqn. (4) in this paper.

$$
\omega_{r}^{*}=0.158 P_{0}^{3}-0.637 P_{0}^{2}+1.118 P_{0}+0.552 .
$$

where $\omega_{r}^{*}$ and $P_{0}$ are the rotor speed reference and PMSG power output, respectively. $P_{0}$ can be calculated by the current $I_{L l}$ flowing through inductor $L_{l}$ as shown in Fig. 2 and the voltage $V_{\text {in }}$ across the capacitor $C_{i n}$ as given below.

$$
P_{0}=V_{i n} I_{L 1}
$$

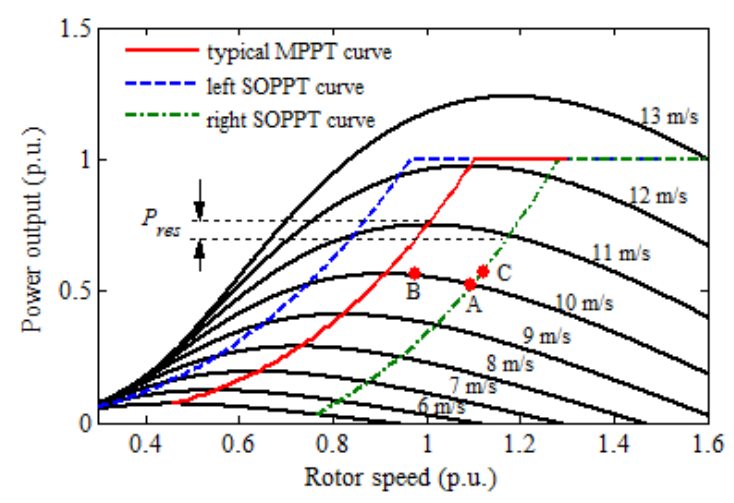

Fig. 3 Wind turbine characteristic curves under various wind speed.

\section{FREQUENCY RESPONSE CONTROL STRATEGY}

As it can be seen in Fig. 2, MSC is not controllable and the GSC is responsible for maintaining the DC-link voltage constant while controlling the power factor of the WECS. Therefore, the frequency response control mainly relies on the control of the boost converter between MSC and GSC, and the bidirectional DC/DC converter coupling $\mathrm{UC}$ to the DC-link. The frequency response control accomplished by these two converters is analyzed in following subsections.

\section{A. Frequency response through boost converter}

As shown in Eqn. (5), by controlling the current flowing through the inductor $L_{l}$, the power output from the wind turbine can be controlled. The UC module is disabled when boost converter is applied to manipulate frequency response from WECS. By regulating the duty of the boost converter gate signal, the frequency response from the wind turbine can be achieved. The detailed controller for controlling the inductor current is illustrated in Fig. 4. The rotor speed reference $\left(\omega_{r}^{*}\right)$ is generated by the tracking curves as shown in Fig. 3 in accordance with the turbine power output $\left(P_{0}\right)$, and rotor speed intends to capture this reference value with a PI controller fed by the error between reference rotor speed and actual rotor speed $\left(\omega_{r}\right)$. 
Therefore, the WECS does not change its power output and no frequency response is provided by the WECS when frequency disturbance occurs in the system. If typical frequency regulation strategy with virtual inertial control and droop control, as shown by Eqn. (6) and Eqn. (7) respectively, are implemented, additional terms reflecting the frequency changes can be added into the controller.

$$
\begin{gathered}
\Delta X_{H}=k_{H} \frac{d f_{s y s}}{d t} \\
\Delta X_{D}=\frac{1}{k_{D}}\left(f_{s y s}-f_{n o m}\right)
\end{gathered}
$$

where, $f_{\text {sys }}$ is the system frequency, $f_{\text {nom }}$ is the system nominal frequency, and $k_{H}$ and $k_{D}$ are the inertial control and droop control coefficient, respectively. The inertial control term emulates the conventional synchronous generator's response to frequency changes. A low pass filter with a constant of $T_{f}$ is added in front of the derivative process to prevent the high frequency noise caused by frequency measurement from affecting the controller performance. The addition of the two terms can be added either into the rotor speed error between rotor speed reference $\left(\omega_{r}^{*}\right)$ and actual rotor speed, or into the inductor current error between inductor current reference ( $\left.i_{L 1}^{*}\right)$ and actual inductor current $\left(i_{L I}\right)$, which results in long term (permanent) frequency response or short term (temporary) frequency response.

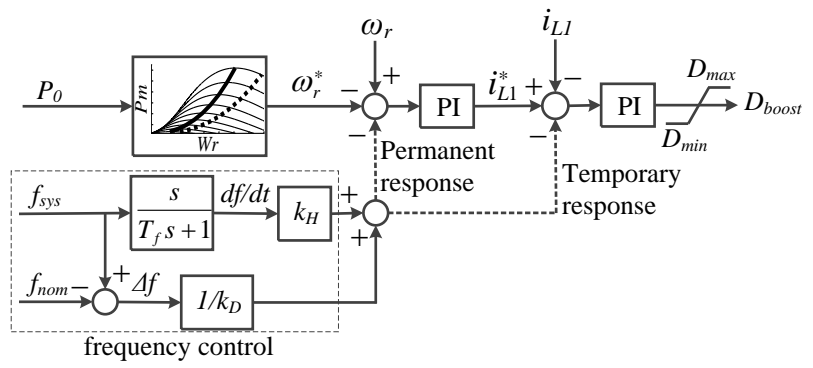

Fig. 4 Frequency response control with boost converter diagram.

1). Long term frequency response: when the sum of the inertial and droop control terms are added to the error between rotor speed reference $\left(\omega_{r}^{*}\right)$ and actual rotor speed $\left(\omega_{r}\right)$ as shown in Fig. 4, the inductor current reference can be determined as,

$$
\begin{aligned}
i_{L 1}^{*} & =k_{P}\left(\omega_{r}-\omega^{*}-\Delta X_{H}-\Delta X_{D}\right) \\
& +k_{I} \int\left(\omega_{r}-\omega^{*}-\Delta X_{H}-\Delta X_{D}\right) d t
\end{aligned}
$$

For example, system originally operates at point $\mathrm{A}\left(\omega_{r A}\right.$, $\left.P_{O A}\right)$ as shown in Fig. 3. A frequency dip contributes to the increase in inductor current and thus power output, and the rotor speed decreases. That is, the wind turbine operating point moves to point $\mathrm{B}\left(\omega_{r B}, P_{O B}\right)$. Meanwhile, the increase in power output causes the rotor speed reference to increase according to the tracking curve to point $\mathrm{C}\left(\omega_{r C}, P_{O C}\right)$. Hence, a negative rotor speed error tends to bring rotor speed back to the original point. However, due to the presence of the frequency control term, the negative rotor speed error can be cancelled out, and the system stabilizes at the new steady state point B where,

$$
\begin{gathered}
P_{0 B}=P_{0 C} \\
\omega_{r B}=\omega_{r C}+\Delta X_{D}+\Delta X_{H} .
\end{gathered}
$$

Therefore, permanent frequency response is obtained as long as permanent frequency deviation occurs in the system. However, permanent frequency response from WECS might not be desirable since power reserve in wind turbine cannot be relied upon. Insufficient power to satisfy the power demand may cause stability problems.

2). Short term frequency response: the sum of the inertial and droop terms is added to the error between inductor current reference $\left(i_{L 1}^{*}\right)$ and actual inductor current $\left(i_{L I}\right)$ as shown in Fig. 4. Similar with long term frequency response explained above, a frequency dip also increases turbine power output to provide frequency support. However, the negative rotor speed error fed to the PI controller reduces the inductor current reference, and a negative error between inductor reference current and actual inductor current is formed and reduces the duty of boost converter gate signal. Thus the power output from WECS reduces. The rotor speed reference equals to the actual rotor speed at steady state and the system recovers to the original operating point. Hence, only temporary frequency response is obatained.

\section{B. Proposed frequency response strategy with UC}

As explained in Section IV-A, the frequency response achieved by controlling the boost converter adjusts the turbine power output rapidly when a frequency event occurs. The WECS participates in frequency regulation and the fast response speed relieves conventional generator from handling the frequency fluctuations. However, the frequent WECS power output adjustment and abrupt sudden torque variations create significant stress on mechanical components of the WECS. The UC is superior in power density and power changing rate, which is capable of relieving the torque stress on wind turbine while providing frequency response. Therefore, short term frequency response control strategy based on UC is proposed as shown in Fig. 5.

The inertial and droop terms for the frequency control are similar with the frequency controller implemented in boost converter control as mentioned in Section IV-A. The only difference is a washout filter [24] is used in the droop control branch. The filter prevents the droop control from being active for permanent frequency deviation considering the limited energy stored in the UC. The power output reference set for UC is thus given by,

$$
P_{U C}^{*}=\Delta P_{\text {res }}-\Delta X_{D}-\Delta X_{H} \text {. }
$$

where, $\Delta P_{\text {res }}$ is power reserve change in the wind turbine. This term is activated when power reserve in the wind turbine is utilized to charge the UC. Certain conditions should be satisfied to enable the utilization of power reserve for UC charging, which are illustrated with the logical diagram shown in Fig. 6. Firstly, state of charge (SOC) of the UC reaches a lower limit, which can be set as 
$25 \%$ (i.e. UC voltage reduces to the half of its rated value). Secondly, the rate of change of frequency (ROCOF) in RAPS system should be within a certain range to ensure the power reserve is not utilized to charge the UC during a frequency event. When the power reserve is enabled for charging, a supplementary control similar to the permanent frequency response control discussed in Section IV-A is added into the boost converter controller as shown in Fig. 7. A PI controller generates the additional control term with error between power output from UC $\left(P_{U C}\right)$ and the power reserve $\left(P_{\text {res }}\right)$ in wind turbine. Hence, the term added to the error between the reference rotor speed and actual rotor speed is given by

$$
\Delta \omega=k_{s P}\left(P_{U C}-P_{r e s}\right)+k_{s I} \int\left(P_{U C}-P_{r e s}\right) d t .
$$

where $k_{S} P$ and $k_{s I}$ are the PI controller parameters. A limiter is used to limit the changing rate of this additional term to avoid torque stress on wind turbine during UC charging. The supplementary control increases the wind turbine power output and the increase in power output $\Delta P$ is absorbed by the UC. Hence,

$$
\Delta P=\Delta P_{r e s} .
$$

Therefore, WECS power output maintains the same as before charging is enabled.

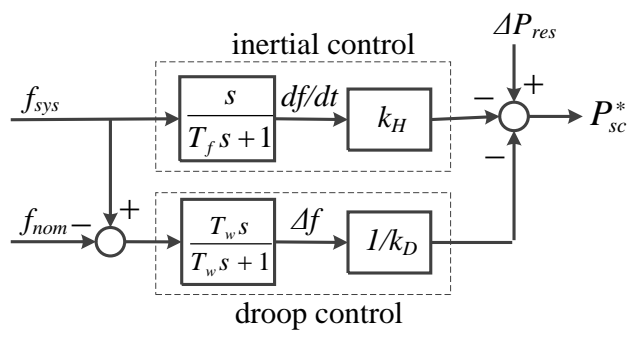

Fig. 5 Frequency response control diagram for UC.

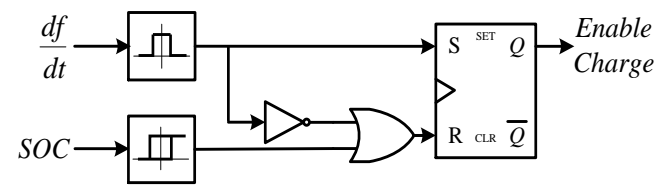

Fig. 6 Ultracapacitor charge logic diagram.

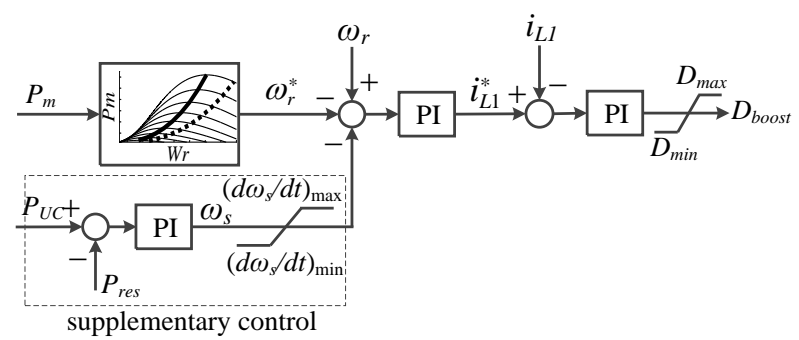

Fig. 7 Boost converter controller with charging supplementary control.

\section{RESUlTS AND DisCUSSIONS}

The RAPS system shown in Fig. 1 is used as test system to validate the effectiveness of the proposed frequency response control strategy in a PMSG based WECS. The proposed controller is compared with the boost converter frequency response controllers in the first case study. In the second case study, the UC charging using the power reserve in the wind turbine is tested. The third case study verifies the applicability of the proposed controller under variable wind speed.

A. Case A: Compaison between UC based frequency response control and boost converter based frequency response control

A frequency disturbance is created by a sudden load increase of $0.3 \mathrm{MW}$ at the time of $\mathrm{t}=40 \mathrm{~s}$. Four scenarios are studied: (1) WECS without frequency response control; (2) permanent frequency response control implemented in the boost converter controller as explained in Section IVA-(1); (3) temporary frequency response control implemented in the boost converter control as explained in Section IV-A-(2); (4) frequency response control implemented in the UC storage system as explained in Section IV-B. The simulation results are shown in Fig. 8. It can be seen from Fig. 8-(a) that any type of frequency response control strategies can improve the frequency performance by reducing the frequency nadir. Fig. 8-(b) shows that the mechanical torque on the turbine shaft is not affected by the load increase in the scenario (1) and (4) whereas a sudden torque increase presents in scenario (2) and (3). Furthermore, torque oscillations are obvious for scenario (2) and (3) which indicates that the soft drivetrain of the turbine is highly stressed. It can also be seen from Fig. 8-(b) that the mechanical torque in scenario (2) stabilize at a higher value after the frequency event whereas the torque returns to the original value for scenario (3), which verifies the difference between permanent frequency response and temporary frequency response. The rotor speed shown in Fig. 8-(c) demonstrates similar results with Fig. 8-(b). The rotor speed does not change for scenario (1) and (4) under frequency event whereas speed deviation occurs permanently and temporarily for scenario (2) and (3) respectively. Although the turbine power maintains the same during frequency variation in scenario (4), the WECS power output increases due to frequency response supplied by the UC as seen in Fig. 8-(d). Without frequency response from wind turbine generator, a step change in the diesel generator power output can be observed following the sudden increase in load as shown in Fig. 8- (e). With the frequency response control, the rate of change of power (ROCOP) on the diesel generator decreases. Therefore, any type of the mentioned frequency response control strategy is able to support frequency regulation while frequency response control applied in the boost converter controller burdens the wind turbine. The frequency response provided by the UC on the DC-link of the wind turbine generator can effectively provide frequency support while alleviating stress on wind turbine. 

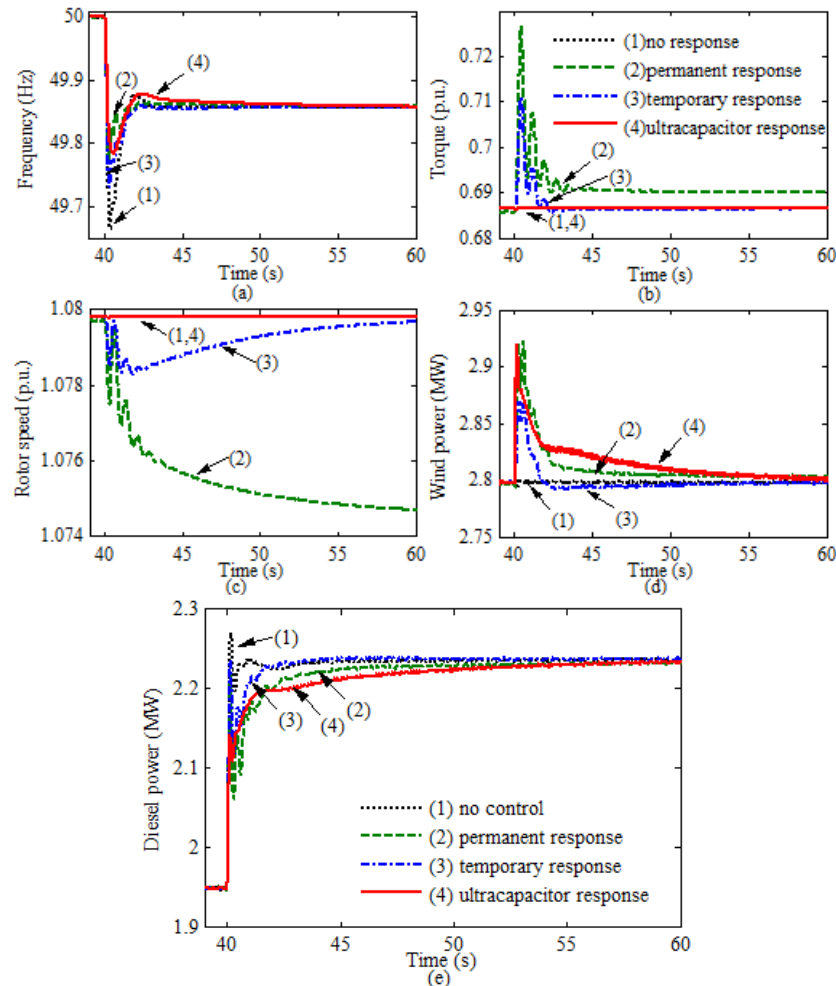

Fig. 8 Comparison between UC based frequency response control and boost converter based frequency response control: (a) system frequency; (b) wind turbine mechanical torque; (c) wind turbine rotor speed; (d) wind generator power output; (e) diesel power output.

\section{B. Case B: UC charging using power resrve in the wind turbine}

The same frequency disturbance is considered in this case as Case A and wind speed is also assumed to be constant. For the purpose of demonstration, the lower SOC limit to activate the UC charging with wind power reserve is set at $98 \%$ in this case. It can be seen from Fig. 9-(f) that the SOC reaches the lower limit after providing frequency response during the frequency disturbance. The charge is activated around $t=75 \mathrm{~s}$. The wind turbine power starts to increase while WECS power output maintains constant, which is opposite in the period when frequency response is provided (i.e. wind turbine power output maintains the same while WECS increases to provide frrequency response). The power difference is absorbed by the UC and the SOC of the UC increases. Since the UC is just slighly discharged, it does not take long to fully charge the UC. After UC is charged to a certain level, e.g. SOC = $99 \%$, wind turbine is controlled to start to decrease its power ouput (as shown in Fig. 9-(d)) to avoid a sudden power increase from WECS when the UC is fully charged and disconnected. The frequency variation is well regulated in a small range as shown in Fig. 9-(a). The permanent frequency variation presents because no secondary governor control is implemented in the RAPS system to bring the frequency back to nominal value.
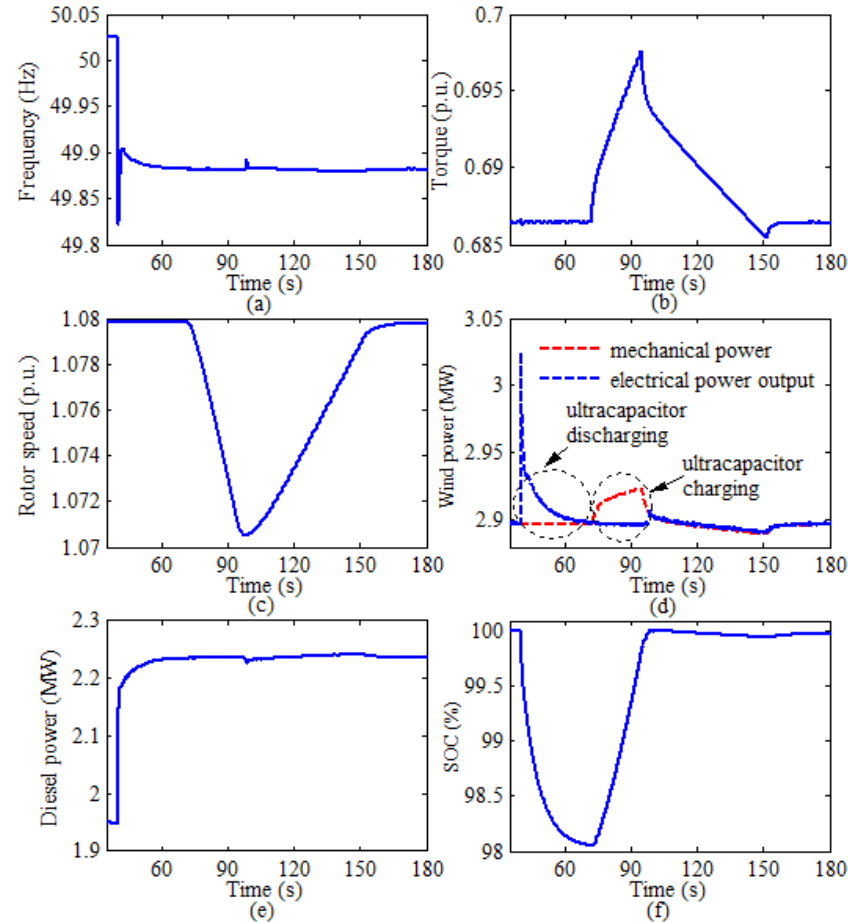

Fig. 9 UC charging using power reserve in the wind turbine: (a) system frequency; (b) wind turbine mechanical torque; (c) wind turbine rotor speed; (d) wind power; (d) diesel generator power output; (e) SOC of UC.

\section{Case C: applicability of the proposed controller under variable wind speed}

In the above two case studies, the wind speed is assumed to be constant. This assumption is generally used for transient study. To further study the frequency regulation capability of the proposed controller, WECS under variable wind speed scenario is investigated in this case study. A wind speed time series profile shown in Fig. 10-(a) is taken as a snapshot of real time wind speed profile. The WECS power output and diesel generator power output (as indicated by the blue dot line in Fig. 10(b) and (c) respectively) are smoothed as compared to their counterparts (as indicated by the red solid line in Fig. 10(b) and (c) respectively) when no frequency response control is implemented in the WECS. Consequently, the variation in system frequency is mitigated as shown by blue dot line in Fig. 10-(d). The smoothing effect in the generator power output attributes to the absorption and injection of power in the UC regulated by the frequency response control strategy. As it can be seen from Fig. 10(e), the SOC of the UC fluctuates denoting continuous charging and discharging of the UC. 

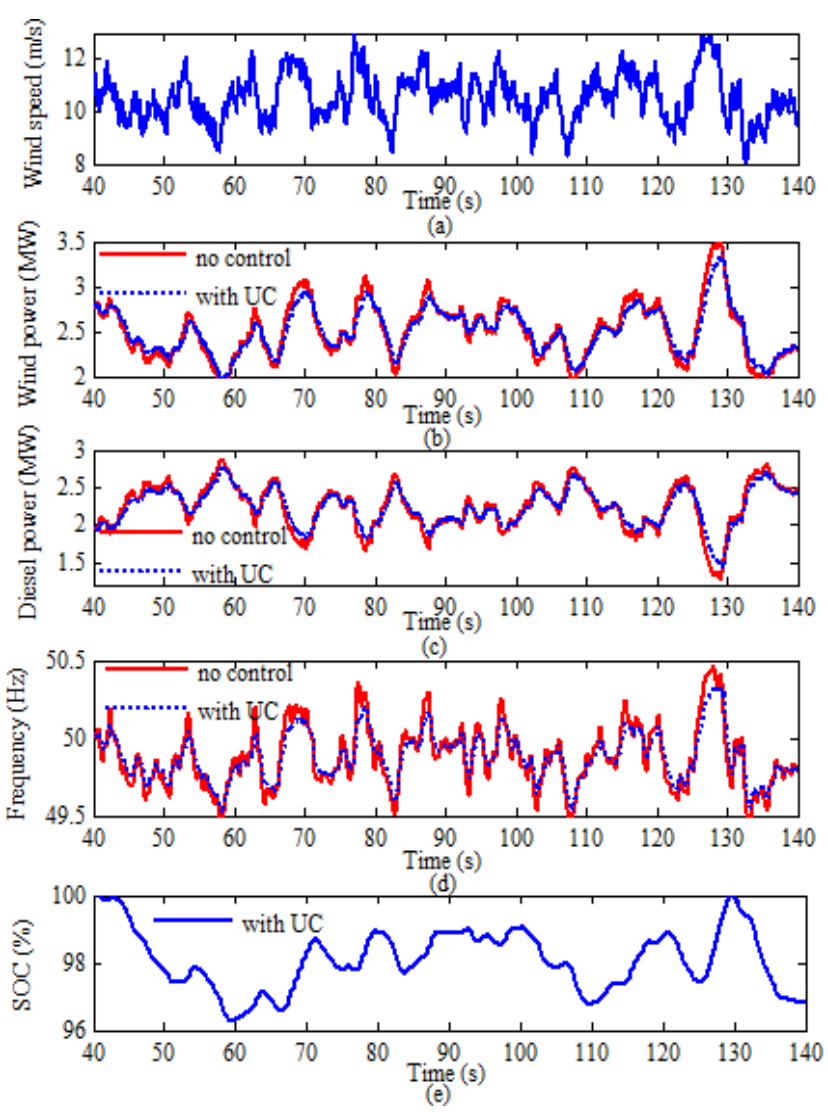

Fig. 10 applicability of the proposed controller under variable wind speed: (a) wind speed profile; (b) wind generator power output; (c) diesel generator power output; (d) system frequency; (e) SOC of UC.

\section{CONCLUSION}

In this paper, an ultracapacitor (UC) based frequency response control strategy is proposed for a PMSG based wind energy conversion system (WECS) with an interfacing converter scheme consisting of a diode rectifier, a boost converter, and an inverter. Droop control and virtual inertial control are implemented in the frequency response controller of the UC. The controller acts on the frequency variation while wind turbine mechanical power output is not affected under frequency disturbance. In this way, the torque stress on both the conventional generator and the mechanical components of the WECS are alleviated while frequency regulation is not attenuated. The proposed UC based frequency response control is compared with boost converter based frequency response control strategy. It is found that shaft torque and rotor speed oscillations are eliminated with the proposed control strategy thus reducing the stress on mechanical components of the WECS. Suboptimal power point tracking strategy (SOPPT) is implemented in the WECS to reserve a part of the wind power for charging the UC when the SOC is low, hence enhancing the effectiveness of the proposed frequency response control strategy. The WECS equipped with the proposed control strategy is also investigated under variable wind speed condition. The results show that power output from the generators is smoothed and frequency regulation is improved. In future work, an improved UC charging algorithm might be developed considering factors such as the ramp rate of power variation in wind turbine, wind power reserve, SOC of the UC, etc, which may further reduce the stress on WECS and improve the frequency regulation capability of the WECS while maintaining the wellbeing of the UC.

\section{APPENDIX}

TABLE I

PMSG PARAMETERS

\begin{tabular}{lccc}
\hline \hline \multicolumn{1}{c}{ Parameter } & Value & Parameter & Value \\
Rated Power & $2.0 \mathrm{MW}$ & $\mathbf{X d}$ & 1.305 p.u. \\
Rated Frequency & $50 \mathrm{~Hz}$ & $\mathbf{X d}$ & 0.296 p.u. \\
Turbine Inertia Contant & $4.32 \mathrm{~s}$ & $\mathbf{X d}^{\prime \prime}$ & 0.252 p.u. \\
Rated wind speed & $11 \mathrm{~m} / \mathrm{s}$ & $\mathbf{X q}$ & 0.474 p.u. \\
Rated Stator Voltage & $400 \mathrm{~V}$ & $\mathbf{X q} \mathbf{q}^{\prime \prime}$ & 0.243 p.u. \\
DC bus voltage & $800 \mathrm{~V}$ & $\mathbf{X I}$ & 0.18 p.u. \\
\hline \hline
\end{tabular}

TABLE II

DIESEL GENERATOR PARAMETERS

\begin{tabular}{lccc}
\hline \hline \multicolumn{1}{c}{ Parameter } & Value & Parameter & Value \\
Rated Capacity & 3.125 & T1 & 0.01 \\
Rated frequency & MVA & T2 & 0.02 \\
Rated Voltage & 50 RPM & T3 & 0.2 \\
Pole Pairs & $2400 \mathrm{~V}$ & $\mathbf{T 4}$ & 0.25 \\
$\mathbf{H}_{\mathbf{d}}(\mathbf{s})$ & 2 & $\mathbf{T 5}$ & 0.009 \\
$\mathbf{T}_{\mathbf{D}}(\mathbf{s})$ & $0.75 \mathrm{~s}$ & $\mathbf{T 6}$ & 0.0384 \\
$\mathbf{H}_{\mathbf{s}}(\mathbf{s})$ & $0.024 \mathrm{~s}$ & $\mathbf{K}$ & 40 \\
\hline \hline
\end{tabular}

\section{REFERENCES}

[1] Y. Tan, L. Meegahapola, and K. M. Muttaqi, "A review of technical challenges in planning and operation of remote area power supply systems," Renew. Sustain. Energy Rev., vol. 38, no. 0, pp. 876-889, 2014.

[2] D. Gautam, L. Goel, R. Ayyanar, V. Vittal, and T. Harbour, "Control strategy to mitigate the impact of reduced inertia due to doubly fed induction generators on large power systems," IEEE Trans. Power Syst., vol. 26, no. 1, pp. 214-224, 2011.

[3] C.-C. Le-Ren, L. Wei-Ting, and Y. Yao-Ching, "Enhancing frequency response control by dfigs in the high wind penetrated power systems," IEEE Trans. Power Syst., vol. 26, no. 2, pp. 710 718,2011

[4] X. Yingcheng and T. Nengling, "System frequency regulation in doubly fed induction generators," Int. J. of Elect. Power \& Energy Syst., vol. 43, no. 1, pp. 977-983, 12// 2012.

[5] M. Kayikci, Milanovic, x, and J. V., "Dynamic contribution of dfigbased wind plants to system frequency disturbances," IEEE Trans. Power Syst., vol. 24, no. 2, pp. 859-867, 2009.

[6] K. V. Vidyanandan and N. Senroy, "Primary frequency regulation by deloaded wind turbines using variable droop," IEEE Trans. Power Syst., vol. 28, no. 2, pp. 837-846, 2013.

[7] C.-C. Le-Ren, S. Chih-Che, and Y. Yu-Ju, "Modeling of wind farm participation in agc," IEEE Trans. Power Syst., vol. 29, no. 3, pp. 1204-1211, 2014.

[8] A. Mullane and M. O'Malley, "The inertial response of inductionmachine-based wind turbines," IEEE Trans. Power Syst., vol. 20, no. 3, pp. 1496-1503, 2005.

[9] S. Benelghali, M. E. H. Benbouzid, and J. F. Charpentier, "Generator systems for marine current turbine applications: A 
comparative study," Oceanic Engineering, IEEE Journal of, vol. 37, no. 3, pp. 554-563, 2012.

[10] J. F. Conroy and R. Watson, "Frequency response capability of full converter wind turbine generators in comparison to conventional generation," IEEE Trans. Power Syst., vol. 23, no. 2, pp. 649-656, 2008.

[11] M. El Mokadem, V. Courtecuisse, C. Saudemont, B. Robyns, and J. Deuse, "Experimental study of variable speed wind generator contribution to primary frequency control," Renew. Energy, vol. 34, no. 3, pp. 833-844, 3// 2009.

[12] I. D. Margaris, S. A. Papathanassiou, N. D. Hatziargyriou, A. D Hansen, and P. Sorensen, "Frequency control in autonomous power systems with high wind power penetration," IEEE Trans. Sustain. Energy, vol. 3, no. 2, pp. 189-199, 2012.

[13] W. Ye, G. Delille, H. Bayem, X. Guillaud, and B. Francois, "High wind power penetration in isolated power systems-assessment of wind inertial and primary frequency responses," IEEE Trans. Power Syst., vol. 28, no. 3, pp. 2412-2420, 2013.

[14] D. Somayajula and M. L. Crow, "An ultracapacitor integrated power conditioner for intermittency smoothing and improving power quality of distribution grid," IEEE Trans. Sustain. Energy, vol. 5, no. 4, pp. 1145-1155, 2014.

[15] C. Abbey and G. Joos, "Supercapacitor energy storage for wind energy applications," IEEE Trans. Ind. Appl., vol. 43, no. 3, pp. 769776, 2007.

[16] R. Sarrias-Mena, L. M. Fernández-Ramírez, C. A. García-Vázquez, and F. Jurado, "Fuzzy logic based power management strategy of a multi-mw doubly-fed induction generator wind turbine with battery and ultracapacitor," Energy, vol. 70, no. 0, pp. 561-576, 6/1/ 2014.

[17] W. Xiaoyu, Y. Meng, E. Muljadi, and G. Wenzhong, "Probabilistic approach for power capacity specification of wind energy storage systems," IEEE Trans. Ind. Appl., vol. 50, no. 2, pp. 1215-1224, 2014.

[18] A. Esmaili, B. Novakovic, A. Nasiri, and O. Abdel-Baqi, "A hybrid system of li-ion capacitors and flow battery for dynamic wind energy support," IEEE Trans. Ind. Appl., vol. 49, no. 4, pp. 16491657, 2013.

[19] R. G. de Almeida and J. A. Peas Lopes, "Participation of doubly fed induction wind generators in system frequency regulation," IEEE Trans. Power Syst., vol. 22, no. 3, pp. 944-950, 2007.

[20] P. Moutis, S. A. Papathanassiou, and N. D. Hatziargyriou, "Improved load-frequency control contribution of variable speed variable pitch wind generators," Renew. Energy, vol. 48, no. 0, pp. 514-523, 12// 2012.

[21] F. Katiraei and M. R. Iravani, "Power management strategies for a microgrid with multiple distributed generation units," IEEE Trans. Power Syst., vol. 21, no. 4, pp. 1821-1831, 2006.

[22] K. E. Yeager and J. R. Willis, "Modeling of emergency diesel generators in an 800 megawatt nuclear power plant," IEEE Trans. Energy Convers., vol. 8, no. 3, pp. 433-441, 1993.

[23] Y. Tan, L. Meegahapola, and K. M. Muttaqi, "Suboptimal mppt control for power management in pv-diesel remote area power supply systems," in Proc. Industry Applications Society Annual Meeting, 2014 IEEE, 2014, pp. 1-8.

[24] J. M. Mauricio, A. Marano, A. Gomez-Exposito, and J. L. Martinez Ramos, "Frequency regulation contribution through variable-speed wind energy conversion systems," IEEE Trans. Power Syst., vol. 24, no. 1, pp. 173-180, 2009. 